\title{
重症頭部外傷に対する低体温法の使用経験
}

\author{
津金 隆一·大矢 昌紀・山本 勇夫·長谷川陽子・松岡 隆則・竹井 太 \\ 伊藤 正治·文正夫 ·野尻健 ·佐藤修
}

\section{Management of Severe Head Injury under Hypothermia}

\author{
Ryuichi Tsugane, Masaki Ohya, Isao Yamamoto, Yohko Hasegawa, \\ Takanori Matsuoka, Futoshi Takei, Masaharu Ito, Masao Bun, Ken NojiRI \\ and Osamu SATO
}

Department of Neurosurgery, Tokai University, Isehara, Kanagawa

\begin{abstract}
Twenty patients with severe head injury were treated under hypothermia with barbiturate and hyperventilation. Indications for hypothermia were 1: younger aged acute head injuries, 2: Glasgow Coma Scale 3 to 5 without severe cardio-pulmonary complications, 3: presence of spontaneous respiration. Hematomas with surgical indications were evacuated before the procedure. Surface cooling was applied with accurate cardio-pulmonary monitoring. Steroid, large dosis of thiopental and hypertonic diuretics were used routinely. Dopamine was administered when the blood pressure was low to maintain the cerebral perfusion pressure of normo-thermia. The average duration of hypothermia at $30^{\circ} \mathrm{C}$ was 6.6 days. In 7 cases with primary brain stem injury, 3 died and 4 recovered with mild to moderate disability. In 13 cases with secondary brain stem injury, 2 died and 3 showed excellent recovery without any defects. Eight cases recovered with mild to moderate disability. The overall mortality rate was $25 \%$ and none remained in a persistent vegetative state. When compared with other series of severe head injury treated with barbiturate and hyperventilation, the mortality and morbidity rates were improved by application of hypothermia.
\end{abstract}

Key words: severe head injury, hypothermia, barbiturate therapy, brain stem injury

\section{Iはじめに}

頭部外傷の治療の目的は外倁㣪の二次的損傷の予防上治 療にあり，外力による脳組織への一次的損傷はどの上うな 治燎法といえども修復することはできないのが奏状であ り，現在の治療法は外傷に続いて発生する血腫や浮腫によ る脳組織の乏血と低酸素状態や脳の変位による脳へルニア の改善を目標上している。CTスキャンや絾血管掫影によ り血腫の彰断精度は上昇し，より的確な手術的治療が可能 となったが, 脳浮腫による頭蓋内王元進や脳幹損傷の場合 の保存的療法にはいまだ十分な治憭指針がなく，良好な治
療成績を上げられる治療方法を模索しているのが現状であ る. 1974年に頭蓋内压在測定しつつ大量のbarbiturate 使用寸る方法が発表され ${ }^{33}$ ，それに上り治療成績は改善し たが，それでも重症例の治燎成縝法悪く满足できる状態で はない。

我々は，重症頭部外傷に対して barbiturate，過呼吸と ともに全身低体温法を行うことを重症頭部外傷の治潦方針 としてきた。本稿では，その方法の評価を行う。

\section{II 対象および方法}

比較的若年の急性期頭部外傷で，高度な意識障害があ
東海大兴脳神経外科

Address reprint requests to: R. Tsugane, M.D., Department of Neurosurgery, Tokai University Oiso Hospital, 21-1 Gakkyo, Oiso-machi, Naka-gun, Kanagawa 259-01.

受稿 1984年6月4 月受理 1984年11月21日 
り，脳幹損傷による四肢の異常運動がみられ，Glasgow Coma Scale(GCS)1513〜 5, 自発呼吸は停止しておらず, 循環・呼吸器系に重篤な合併症のない例を適応とした。手 術適応のある血腫を有する場合に注，開頭により血腫除去 術を行い，その偻の状態により適応を決定した。

気管内插管により Servo ventilator 900C(Siemens-Elema, Sweden)に接続し, $\mathrm{PaO}_{2} 100 \sim 150$ torr, $\mathrm{PaCO}_{2} 20 \sim 30$ torr の範囲になるよう呼吸器の条件を設定した。. Steroid (dexamethasone $16 \sim 20 \mathrm{mg} /$ day), thiopental (nembutal $1 \sim 4$ $\mathrm{mg} / \mathrm{kg} / \mathrm{hr}$ ) 灰梢静脈より乳酸リンゲル液に混入して持繶 注入し，平均血厅が $100 \mathrm{mmHg}$ 以トになる場合には中心 静脈より dopamine $(10 \sim 20 \gamma \mathrm{g} / \mathrm{kg})$ を持続注入した。主た 頭蓋内正を測定した症例では，低体温中も脳灌流圧(平均 血庄一平均頭蓋内厈) が $65 \mathrm{mmHg}$ 以上となる上う血圧の コントロールに努めた。低体温は，ブランケットによる体 表面冷却により，直腸温を $30^{\circ} \mathrm{C}$ 前後に 7 日間保つことを 目摽とした。自発呼吸，戦㟳が出現した場合には，barbiturateの增量とともに筋驰緩剂(ミオブロック）も適宣使 用した，低体温法施行中法特に心・肺系のモニターを爰重 に行い，12誘導心菴図，胸部X線写真は少なくとも1日1 回検査した，通常の神経学的娭査は瞳孔症状を除いて判定 不能となるため, CT・脳波・誘発電位などの検査を必要 に応じて加えた，経過中は，10\% glycerol $300 \mathrm{ml}$ ，または $20 \%$ mannitol $150 \mathrm{ml}$ を 1 日 2 回点滴静注し，3 日目より 中心静脈栄養法により $1,200 \sim 1,500 \mathrm{Cal} / \mathrm{day}$ 程度を補积 し， 5〜6日目に気管切開を施行した。 また，消化管出血 の予防のため制酸剤( maalox $240 \mathrm{~m} l /$ 日，分 6$)$ を投与し， cimetidine $(800 \mathrm{mg} /$ 日，分 4$)$ を使用した。

低体温法の終了は，7日問以上経過した場合，岀側瞕孔 散大固定など脳の機能が停止したと考えられた場合，ある い治俄症によりやむなく中断した場合であった，終了の 際には，まずブランケット加温により直腸温を $37^{\circ} \mathrm{C} に$ 復 温し，ついで barbiturate，筋驰緩剂を中止し，自発呼吸 の出現を確かめて呼吸器を除去した。

\section{III 結 果}

20症例に低体温法を施行した，症例の年齢分布は，若年 者を適応としたため20才以下が12例であった(Fig. 1)，受 傷より低体温開始までの期間は，受傷当日（０日）が13例， $1 \sim 3$ 日が 5 例，4〜7日が 2 例であり，受傷上り数日以 上経過した症例は経過中の症状増悪により適応となったも のであった。また受傷原风は，交通事故15例( $75 \%)$ ，転落 4 例 (20\%)，打撲 1 例 ( $5 \%$ ) であった。低体温開始直前の 意識状態および神経症状は Table 1 に示すごとく，全例 GCS $3 \sim 5$ で, 瞳孔不同 6 例, 一側散大固定 4 例, 両側

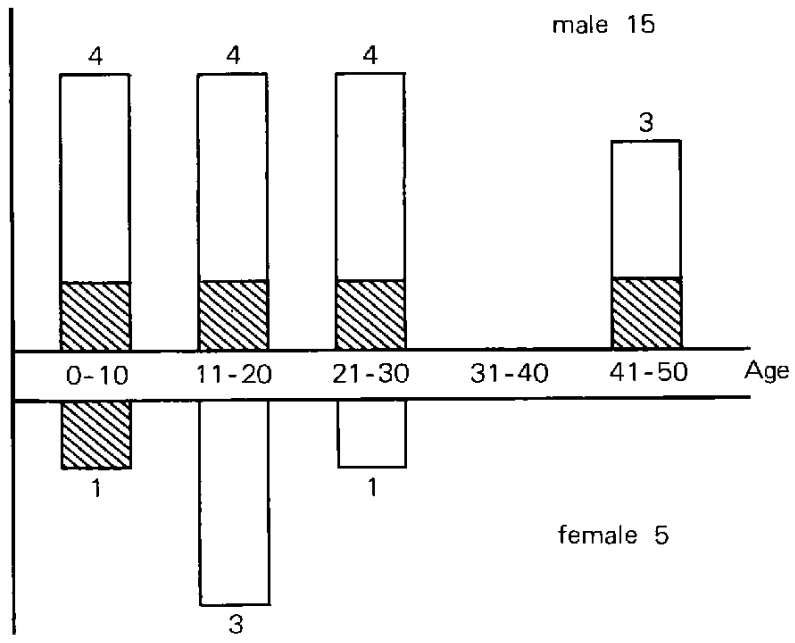

Fig. 1 Age and sex distribution of cases treated under hypothermia. Numbers located at the top and bottom end of a bar indicate number of cases in each age group. Striped zone indicates dead cases.

Table 1 Neurological and physical state of the cases just before the induction of hypothermia

Sensorium

GCS 5

7 (cases)

$\operatorname{GCS} 4$

9

$\mathrm{GCS} 3$

4

Pupils

isocoria 5

anisocoria 6

one side dilated 4

bilaterally dilated $\quad 5$

Respiration

hyperventilation 4

Cheyne-Stokes 1

on respirator 2

Hyperthermia present 7

Associated injuries

fracture of bone*
pulmonary injury
abdominal injury

* Skull fracture is not included in the fracture of bone. GCS indicates Glasgow Coma Scale. ${ }^{15}$ !

散大固定 5 例であった。呼吸状態は，過呼吸 4 例，開頭術 後で呼吸器装着中 2 例, Cheyne-Stokes 呼吸 1 例であっ た，過高熱・発汗などが 7 例に認められ，四肢・軀幹の骨 折，胸・腹部の臟器損傷などの合併損傷を12例に認めた。 
Table 2 Computerized tomography (CT) findings and performed operations in the cases treated under hypothermia

\section{Primary brain stem injury \\ HDA in brain stem \\ SAH in basal cistern \\ obliteration of basal cistern \\ not performed \\ Secondary brain stem injury

intracerebral hematoma
subdural hematoma
epidural hematoma
brain contusion
brain swelling

Operation

intracerebral hematoma
subdural hematoma
epidural hematoma
contusion

7 (cases)

2

2

2

1

13

$3(1)$

$1(1)$

$4(0)$

$5(5)$

$0(6)^{*}$

9

3

1

4

1
*Two cases with intracerebral hematoma and four epidural hematomas were operated, and deteriorated into GCS 3-5 in the postoperative period by massive brain swelling. $\mathrm{CT}$ findings just before the induction of hypothermia are shown in the parenthesis. HDA indicates high density area; SAH, subarachnoid hemorrhage.

朣孔症状については，出現してからの時間が知く，，ｍ－ nitol, glycerol, steroid などに反応して改善を示した提例で あり，両側散大固定の状態が数時閒以上続き固定した症状 となった症例は含まれていない。

臨床症状とCT 所見 (Table 2) 上り一次的脳幹損傷と考 えられたのは7例で，そのCT 所見は中脳・橋の実質内に 高吸收域老認めたものが 2 例，訤低部のクモ膜下出血 2 例，クモ膜下腔の消失を認めたものが 2 例であり，1例は CTが施行されず臨床怔状のみより竝断した。二次的脳幹 損傷と考えられたのは13例で，脳内血腫 3 例，硬膜下血腫 1 例，硬膜外血腫 4 例，脸挫傷 5 例であり，それらのうち 9 例に開頭術が施行された。低体温開始直前のCT 所見と しては, 脳内血腫 1 例, 硬膜下血腫 1 例, 訤挫傷 5 例, 脳 腫脹6例であり, 開頭血腫除去術後に脳内血腫 3 例中 2 例 と硬膜外血腫の 4 例が脳腫脹のため低体温法を施行され た.

低体温法の実施期間は2 16日で，平均6.6日であった。 この期間內にみられた合併症としては(Table 3)，心機能 に関するものでは心電図上のST下降 4 例， A-V ブロッ ク 4 例, $40 / \mathrm{min}$ 以下の徐脈 3 例, 血圧低下 2 例, 心停止 1 例があり，11例14件の異常所見を認めた。肺合併症は 4
例( 6 件)に発生し，無気肺 2 例，肺炎 2 例，気胸 2 例であ った，之の他，消化管加らの大量出血を2例に，尿崩定を 1 例に認めた。電解質異常を 9 例に認め，その内訳は血清 $\mathrm{Na} の$ 上昇が 3 例，低下 1 例 (正常範囲136 $144 \mathrm{mEq} / l$ ), 血清 $\mathrm{K}$ 上昇 4 例，低下 6 例（正常範囲 $3.4 \sim 4.8 \mathrm{mEq} / l$ ) で， 尿素・窒素上昇 1 例(正常範团 男性 $8 \sim 19 \mathrm{mg} / \mathrm{d} l$, 女性 7 〜18)であった，尿崩症の 1 例を除く他の 8 例は，電解質 の in/out バランスの乱れと脱水によるものであり，補正 により正常範国に入った，頭盖内压は，一次的脳幹損傷 2 例括よび二次的脑幹損傷 6 例に招いて，脳空穿刺または硬 膜外ストレンダージ法に上り斬続記録したが，直腸温 $30^{\circ} \mathrm{C}$ でも基礎圧が $35 \mathrm{mmHg}$ 以上であったのは脳挫傷の 2 例のみであった。

受伤後 6 力月を経過した時点で判定した予後 (Table 4) は，死亡は20症例中 5 例であった。一次的脳幹損傷 7 例の 5 ち, good 3 例, fair 1 例, dead 3 例で, 二次的脳幹損傷 13 例では excellent 3 例, good 7 例, fair 1 例, dead 2 例 だ，植物状態( poor)人の移行例はなかった。

Table 3 Various complications encountered during hypothermia

Cardiac 11 (cases)

ST depression, A-V block, bradycardia, hypotension, cardiac arrest

Electrolyte unbalance

Pulmonary atelectasis, pneumonia, pneumothorax

Gastrointestinal bleeding 2

Diabetes incipidus 1

A-V block indicates atrio-ventricular block.

Table 4 Results of treatment under hypothermia

\begin{tabular}{lccc}
\hline & $\begin{array}{c}\text { Primary brain } \\
\text { stem injury }\end{array}$ & $\begin{array}{c}\text { Secondary brain } \\
\text { stem injury }\end{array}$ & $\begin{array}{c}\text { Total } \\
\text { (cases) }\end{array}$ \\
\hline Excellent & 0 & 3 & 3 \\
Good & 3 & 7 & 10 \\
Fair & 1 & 1 & 2 \\
Poor & 0 & 0 & 0 \\
Death & 3 & 2 & 5 \\
\hline \multicolumn{1}{c}{ Total } & 7 & 13 & 20 \\
\hline
\end{tabular}

Excellent: no residual defects, Good: mild residual defects but able to return to previous occupation or attend to school, Fair: moderate to severe disability in home life but self care possible, Poor: persistent vegetative state with total disability. 


\section{IV 考察}

低体温法は, 1950年代の後半上り60年代に实験的研究や 臨床店用が行われ，脳神経外科領域でも脳代謝の低下に上 る脳血流遮断時間の延長と兴血流量の低下に上る頭蓋内历 下降の月的で使用された1,8,22．頭部外傷に対する低体望 法の応用も同時期より発表されており，方法としてはすで に30年近い歴必をむっていることになる。しかし，最近で は頭部外傷の治療法として心用されることはほとんどな く, barbiturate 療法が主流となっている。低体温法の施行 は繁雑で合併症が多いこと，また $2 \sim 3$ 日間の低体温では ト、昇していた頭蓋内圧が復温後に下降を示すことはほとん ど無理なため，治療成績が向上せず顧みられなくなったも のと推定される.

そこで我々は，通常の barbiturate 黁法に加えて低体温 法在行い，持続期間を7日間とした，その際血液ガス分 析, 電解質唡査, 心電図娭查などに加えて, 向圧が常温時 と同じかあるいは常温々同一の脳灌流玨を維持するよう最 大限の注意を払いつつ, 低体温法を施行した。しかし， barbiturate 療法中や低体温中の血圧を，正常状態上问程 度に維持することが商当であるのか否が，いまだ定説は ない. 特に急性期頭部外傷の症例で, 脳循環の白動能が失 われている場合に血圧を上萃させると，かえって悪影偣が 出る症例もありうると考えられる14!。しかし，血王が低い
ままで経過し，脳灌流圧が維持できず脳死となったと考 えられる症例があり，その拝例を経験してからは血圧を正 常状態と同じ籣囲に入るように方針を変更している.この 点については今後の㛟討を要するものと考える。

種々の合併症のうち，心機能に関するむのでは A-V ブ ロック，徐脈などが注意を要し，特に dopamineによって も上算しない低血圧の場命性低体温法を中止せざるをえな い. 電解質の不圲衡泣頻度が高いが，早期に補正すること で容易に正常化した。脳队血腫の術後に低体温を開始した 症例の脳室内厈をFig. 2 に示す. 常温では30〜 40 mmHg の基礎圧で頻回に圧波が出現したが，体温の下降とともに 基礎压沈下降し王波は消失して安定した脳室压となった。 この状態のまま 7 日間を经過し復温した. 大脳半球の占拠 性病变によって生じた二次的脳幹損傷例は，頭蓋内圧が高 いため低体温法の上い適忘と考えられ，死亡は13例中 2 例 であった，そのうち1例は初期の例で，前述の低血厈のた めに兴死となったと考えられた. Mannitol, glycerol など の高渌透压剂の使用方法は，血液を比較的高浸透圧におく ため，頭蓋內压に関係なく比較的少量を1日2回点滴し た。頭蓋内厈测定しつつ一定の限界老越光たときに使用 するのが一般的であるが, この方法では一時的な頙䒨内圧 の下降が得られるのみで，使用回数が増加するにつれて効 果は減少し，しだいに電解質のバランスが乱机非ケトン性 高近楉症が発生することが多い。高浸透圧剂のみにより，

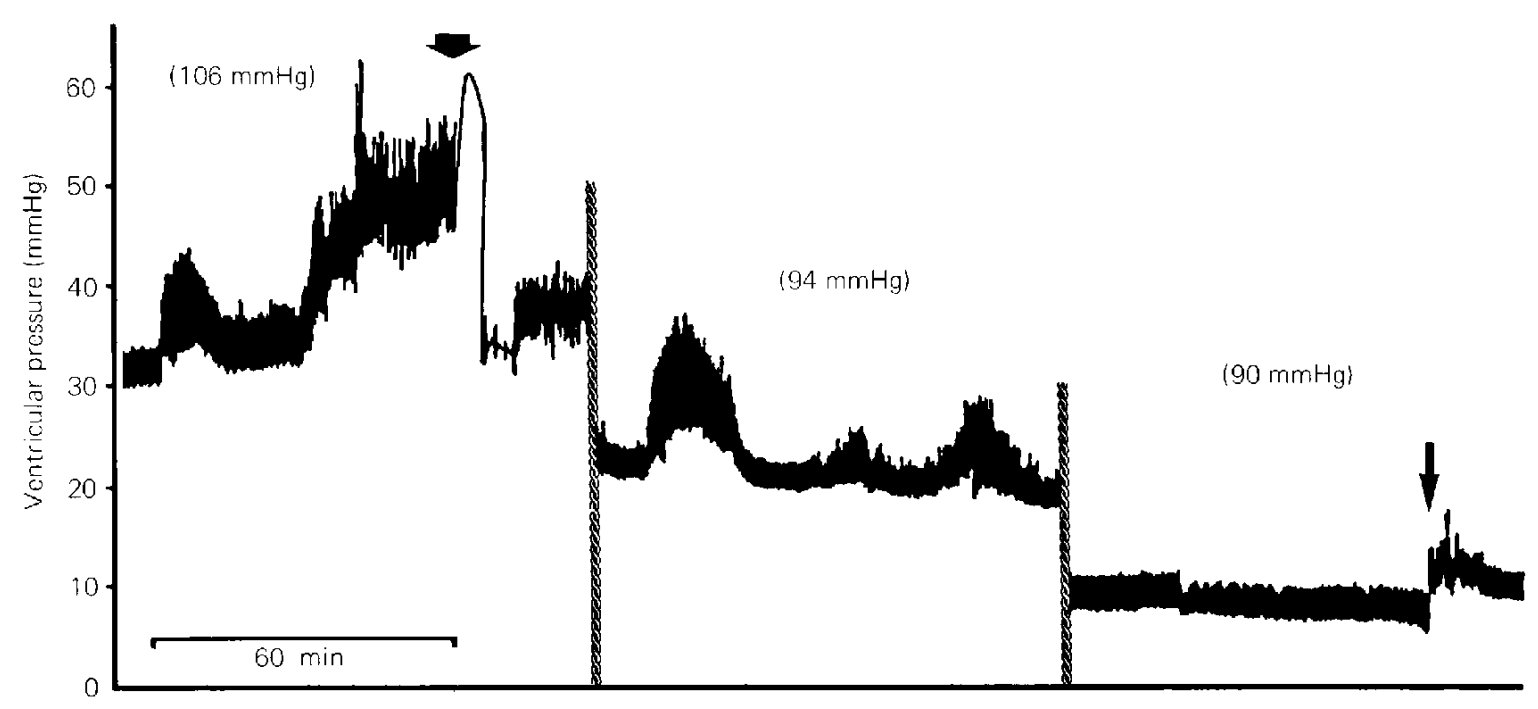

Fig. 2 Serial tracing of ventricular pressure in a patient with multiple intracerebral hematoma during induction of hypothermia at threc different rectal temperatures. In the left column, multiple pressure waves with elevated basal pressure can be seen at $36.4^{\circ} \mathrm{C}$. $\mathrm{A}$ thick arrow indicates opening of the ventricular drainage. In the middle column, the rectal temperature is lowered to $34.2^{\circ} \mathrm{C}$ and the basal pressure is around $20 \mathrm{mmHg}$ with persistent pressure waves. In the right, pressure tracing is shown during the stable state of hypothermia at $31.5^{\circ} \mathrm{C}$. The basal pressure is about $10 \mathrm{mmHg}$ and is stable. The thin arrow indicates suction on the tracheal tube and change of body position. The mean systemic arterial pressure is shown in the parenthesis. 
持繶的に上昇した急性期頭部外傷の頭蓋内庄管理を行うこ とはむしろ危険であり，持続効果の期待できる過呼吸， barbiturateや低体温法を同時に施行寸るのが良策と考え る.

一次的脳幹損傷の䛦断は，CT 上で脸幹部に高吸収域が みられ臨床症状と合致している場合は比較的容易である が，大脳半球病変合併している場合や，受傷迫後の CT には異常がなくfollow-up CTにて脳幹周辺のクモ膜下出 血や脳槽の閉塞がみられるようになる場合があり 4.5.11), CTだけでは診断できず常に臨床佂状圭加味して診断し た。一次的脳幹損傷例では， 7 例巾 3 例 $(43 \%)$ 无死亡し， 生存した症例でもなんらかの後遗症状を残したが，四肢筋 あるい性関節の拘縮など四肢運動障害が主体で、意識障害を 残した症例注なかった。同一期间内に加㙩した䫓部外傷例 で，年齡，合併症，その他の理由で低体温法をせずに barbiturate 療法のみが施行された一次的脳幹損傷例では, 椎 物状態への移行例が半数を古めたが，低体温施行例では植 物状態への移行例がない点を強謂したい，治療成績を他の 報告に比較してみる場合に，神経症状の評価が医師閒で差 が出たり症例の重症度が一致しないなどの閣題があり，必 ずしも正当な比較ができない場合が多いが3,7，重症頭部 外傷で GCS 3〜 5 範囲では barbiturate 療法によっても 死乞率は $50 \%$ を越えている $2,6,9,10,16)$ 。これらの報告と比較 すると，我々の症例は若年者を選んで括り心・肺系の重篤 な合併掟例を除外した点などさまざまな相違点がみられる が、そうした点を考慮しても低体温法に上り治療成績が向 上したと言ってよいものと信じている.

本論文の要旨は, 第 7 回日本神経外傷研究会(1984年 2 月, 大 阪)において発表した。

\section{文献}

1) Bering EA, Taron JA, McMurrey JD, Bernhard WF: Studies on hypothermia in monkeys. II. 'The effect of hypothermia on the general physiology and cerebral metabolism of monkeys in the hypothermic state. Surg Gynec Obstet 102: 134-138, 1956

2) Gale JL, Dikmen S, Wyler A, Temkin N, McLean A: Head injury in the pacific northwest. Neurosurgery 12: 487-491, 1983
3) Gelpke GJ, Braakman R, Harrema JDF, Hilden J: Comparison of outcome in two scries of patients with severe head injuries. I Neurosurg 59: 745-750, 1983

4) George B, Turel C, Pierron D, Raganea JL: Frequency of primary brain stem lesions after head injuries. A C'T scan analysis from 186 cases of severe head trauma. Acta Neurochir (Wien) 59: $35-43,1981$

5）小林士郎，中沢省三，有賀徹，矢埜正実，大䏒敏文，西 邑信男, 本田一莪：外傷性脳幹部損傷一 CT scan 上 high density を呈した症例より一。兴种外科 8：1165-1174, 1980

6) Levati A, Farina NL, Vecchi G, Rossanda M, Marrubini MB: Prognosis of severe head injuries. $J$ Neurosurg 57: 779-783, 1982

7) Maas AIR, Breakman R, Schouten HLA, Minderhoud M, Zomeren AH: Agreement between physicians on assessment of outcome following severe head injury. $J$ Neurosurg 58: 321-325, 1983

8) McQueen JD, Jeanes LD: Influence of hypothermia on intracranial hypertension. J Neurosurg 19: 277-288, 1962

9) Miller JD, Butterworth JF, Gudeman SK, Faulkner JE, Choi SC, Selhorst JB, Harbison JW, Lutz HA, Young HF, Becker DF: Further experience in the management of severe head injury. $J$ Neurosurg 54: 289-299, 1981

10) Rea GL, Rockswold GL: Barbiturate therapy in uncontrolled intracranial hypertension. Neurosurgery 12: 401-404, 1983

11) Rosenblum WL, Greenberg RP, Seelig JM, Becker DP: Midbrain lesions. Frequent and significant prognostic feature in closed head injury. Neurosurgery 9:613-620, 1981

12) Rosomoff HL, Holiday DA: Cerebral blood flow and cerebral oxygen consumption during hypothermia. Amer J Physiol 179: 8588,1954

13) Shapiro HM, Wyte SR, Loeser J: Barbituratc augmented hypothermia for reduction of persistent intracranial hypertension. J Neurosurg 40: 90-100, 1974

14) Symon L, Braston NM, Strong AJ: Autoregulation in acute focal ischemia. An experimental study. Stroke 7: 547-554, 1976

15) Teasdale G, Jennett B: Assessment of coma and impaired consciousness. A practical scale. Lancet 2: 81-84, 1974

16）矢埜正夷, 横田裕行, 小林士郎, 山本保博, 大塚敏文：重 疜頭部外傷におけるICPと予後との相関. Neurol Med Chir (Tokyo) 23: 336-342, 1983

〔別刷請求先： $\mathbf{T} 259-01$ 神奈川県中郡大磯町月京21-1，東海大 学大磯病院脳神経外科, 津金隆一] 